\title{
DELIMITACIÓN DEL DAÑO MORAL A TRAVÉS DE CONSIDERACIONES DE JUSTICIA DISTRIBUTIVA
}

\author{
DELIMITATION OF THE NON-PECUNIARY DAMAGES \\ THROUGH DISTRIBUTIVE JUSTICE CONSIDERATIONS
}

\author{
FABIÁN A. GONZÁLEZ CAZORLA* \\ Profesor de Derecho Civil \\ Universidad Católica Silva Henríquez \\ Santiago - Chile
}

\section{RESUMEN}

Este artículo pretende mostrar las consideraciones de justicia distributiva que pueden estar incorporadas en el resarcimiento de los daños, especialmente en el daño moral, por responsabilidad contractual y extracontractual. En lo contractual se verá que el contrato, sólo en algunos casos, distribuye derechos e intereses extrapatrimoniales. En lo extracontractual, se reflexiona respecto de una versión del derecho de daños que cuestiona la simple interacción privada entre las partes, ingresando en un terreno social y público que puede dejar en evidencia que lo privado no es tan privado y que existen condiciones sociales que ayudan a distribuir o asignar de mejor forma los derechos o intereses a los miembros de la comunidad, y por lo tanto delimitar los contornos del derecho a ser indemnizado.

Palabras clave: Derecho de daños; daño moral; justicia correctiva; justicia distributiva.

\footnotetext{
* Abogado. Licenciado en Ciencias Jurídicas Universidad Andrés Bello. Postgraduado en Derecho Universidad de Castilla-La Mancha (España). Magíster en Filosofía Aplicada Universidad de los Andes (Chile). Candidato a Magíster en Derecho mención Derecho Privado Universidad de Chile. Profesor de Derecho Civil, Universidad Católica Silva Henríquez. Comentarios al correo electrónico: fab.gon.cazorla@gmail.com. Archivo recibido el 10 de mayo de 2017 y aceptado para su publicación el 26 de julio de 2017.
} 


\section{ABSTRACT}

This article pretends to show the distributive justice considerations which could be incorporated in compensation of the damages, especially regarding nonpecuniary damage, from contractual liability and tort law. In contract law, it will look that contract, only in some cases, distributes rights and interests nonpecuniary. In tort law, it is thought on a version of the tort law which criticize regard the simple private interaction between the parts, entering a social and public area which can show that the private is not so private and that there are social conditions that help to distribute the rights and interests to members of society, and therefore determine the form of the right to compensation.

Keywords: Tort law; non pecuniary damages; corrective justice; distributive justice.

\section{INTRODUCCIÓN}

Al día de hoy la dogmática civil sólo se ha preocupado de la interacción dañosa que se produce entre dos agentes en dos tipos de relación. Una en el ámbito contractual por el incumplimiento, la otra en la extracontractual por la lesión de un interés jurídicamente relevante. Esto quiere decir que sólo se ha efectuado una reflexión que dice relación con el evento dañoso, sus consecuencias y la rectificación de aquel por el agente dañador, dejando de lado algunos criterios de justicia distributiva que pueden evidenciarse en la relación convencional, como en aquella que tiene lugar a raíz de un ilícito extracontractual.

Referirse a este punto implica, desde luego, profundizar sobre los cuestionamientos que tienen lugar respecto del ejercicio de la acción indemnizatoria, tanto en su estructura y su fundamento, de modo que el análisis se torna atractivo cuando se piensa en la justificación de la obligación resarcitoria y los problemas asociados a ella en un espectro reducido de daños: el daño extrapatrimonial.

Respecto del daño extrapatrimonial (o moral), se pueden plantear algunas consideraciones que se refieren a su conceptuación, delimitación y justificación que no están del todo claros. En el ámbito contractual estas nociones se evidencian de una manera más clara comparado con lo que ocurre en sede extracontractual, ya que por ser el contrato un mecanismo privado que permite una mejor comprensión de la relación entre las partes, ésta se articula sobre supuestos ya conocidos (derechos, intereses y riesgos que podrían estar cubiertos por la convención), a partir de los cuales cobra sentido 
y significación aquello que se pretende proteger si de indemnización de daños se trata. En cambio, en la responsabilidad aquiliana pueden presentarse ciertas dificultades que no son fáciles de sortear, pues tradicionalmente la mirada está enfocada en el daño y no en la estructura completa de la relación entre agente dañador y víctima, lo cual permitiría razonar sobre la base de los derechos y deberes correlativos, delimitando entonces la libertad y la seguridad que cada uno posee respectivamente.

De esta forma, en el derecho de daños, preguntarse sobre su justificación implica referirse a los fundamentos teóricos de la obligación que tiene un agente dañador de compensar o indemnizar cuando ha causado un daño a otro, y del derecho correlativo de la víctima a ser compensada. ${ }^{1}$ En otras palabras, la interrogante que se plantea consiste en cómo es posible derivar un derecho a ser indemnizado a raíz de la afectación de un bien jurídico de la víctima; pues ser dañado y el derecho a ser compensado resultan ser dos ideas analíticamente diferentes. Es decir, del hecho que alguien sea dañado (en su propiedad o integridad física) no se sigue inmediatamente que deba ser compensado, ya que no hay continuidad lógica (ni analítica) en esta afirmación. ${ }^{2}$ De hecho, si se opta por el derecho de daños como régimen que se encargue de corregir los infortunios que tengan lugar en la sociedad, este podría ordenar una consecuencia distinta a la reparación en dinero ${ }^{3}$. Por lo que, reflexionar sobre los fundamentos implicados en la obligación de compensar, y en la estructura que tendría el derecho de daños como alternativa que sirva para explicar la distribución de las pérdidas y ganancias a raíz de un ilícito, resulta ser altamente atractivo porque ofrece una explicación acerca de por qué debemos reparar los daños que nos causamos los unos a los otros.

El debate académico se ha hecho notar a través de diversos trabajos que intentan dar cuenta de los fundamentos del derecho de daños, desarrollados principalmente en el derecho anglosajón, no obstante -de manera principal-

\footnotetext{
1 Papayannis, Diego M., Comprensión y Justificación de la Responsabilidad Extracontractual, Marcial Pons, Madrid, 2014, p. 134.

2 Lo mismo sucede cuando se afirma que el que daña sea la misma persona que debe compensar, lo que tampoco es analíticamente equivalente. Véase PINo EMHART, Alberto, "Entre la reparación y la distribución: La responsabilidad civil extracontractual como mecanismo de distribución de infortunios", Revista Chilena de Derecho Privado, 2013, № 21, p. 97.

3 Si el derecho de daños constituye una respuesta a la producción de un daño (cumplidos los requisitos legales), éste no necesariamente debe reducirse siempre a la compensación. La dogmática civil ha sostenido que la reparación es uno de los tantos fines que tiene el derecho de daños, como también lo son la disuasión o el castigo en algunos casos, por lo que optar exclusivamente por la reparación suena apresurado si no se cuenta con los antecedentes y argumentos que justifiquen esta decisión. Véase Diez-Picazo, Luis, Derecho de Daños, Civitas, Madrid, 1999, pp. 42 y ss.
} 
han tomado el protagonismo dos teorías que pretenden explicar los principios implicados en esta área del Derecho. ${ }^{4}$ Uno de ellos es el Análisis Económico del Derecho (AED) ${ }^{5}$, el cual pretende mostrar que los criterios económicos -como la eficiencia- son los que mejor pueden explicar la teoría y la práctica de la responsabilidad extracontractual. ${ }^{6}$ La segunda alternativa es la justicia correctiva aristotélica, que sirve como método explicativo de la interacción entre un agente dañador y la víctima -a través de una vinculación directa, bilateral y relacional- y que adicionalmente podría dar cuenta de los aspectos relevantes del derecho privado en general. ${ }^{7}$

No obstante lo anterior, por la inmensa tarea que implica profundizar sobre los fundamentos teóricos del derecho de daños, lo que no es el propósito de este trabajo, sólo haré referencia a las consideraciones de justicia distributiva que inciden directamente en los perjuicios reclamables, con especial énfasis en el resarcimiento del daño moral.

En cuanto a la aplicación de criterios de justicia distributiva en el derecho de daños, es necesario abandonar el paradigma que entiende que las interacciones injustas o dañosas sólo pueden ser explicadas por el principio de justicia correctiva. Una lectura que sólo se centre en el aspecto rectificador de la conducta deja de lado otras consideraciones que pueden tener tanta (o más) importancia para analizar los diversos casos que se dan en la jurisprudencia. Por lo tanto, plantear una idea más igualitaria del derecho de daños que mezcle aspectos de justicia distributiva y correctiva, puede ser un camino más complicado, a la vez que puede revelar cierta inteligibilidad que dé cuenta de un sentido distinto del "problema de los daños", tal como lo han hecho otros autores sobre la materia. ${ }^{8}$

Los casos que han llegado a los ojos de la jurisprudencia $-\mathrm{y}$ que serán debidamente citados- son aquellos en que además de solicitar la compensación de los daños patrimoniales, se incluyen aquéllos de carácter extrapatrimonial de la víctima. La idea de detenerse mayormente en esta última clase de perjuicio tiene por finalidad comprender el razonamiento del juez en la atribución de responsabilidad del demandado y la asignación de la obligación indemnizatoria,

${ }^{4}$ Barros Bourie, Enrique, Tratado de Responsabilidad Extracontractual, Editorial Jurídica de Chile, Santiago, 2006, pp. 34-35.

5 Una de las obras principales es CoAse, Ronald, "The Problem of Social Cost", The Journal of Law and Economics, 1960, $\mathrm{N}^{\circ} 3$, pp. 1-44.

6 Posner, Richard, "The concept of Corrective Justice in Recent Theories of Tort Law", The Journal of Legal Studies, 1981, № 10, pp. 187-206.

7 WeInRIB, Ernest, Corrective Justice, Oxford University Press, Oxford, 2012; WeInRIB, Ernest, La idea de Derecho Privado (Trad. Eze Páez), Marcial Pons, Madrid, 2017.

8 Véase especialmente PAPAYAnNIS, cit. (n. 1). 
identificando si éste se reduce a una cuestión de mera discreción o valoración prudencial, o bien si implica otro tipo de razonamiento que se traduzca en las consideraciones especiales de las partes del litigio que lo lleve a la rectificación del injusto mediante la imposición de la indemnización como una medida para paliar la situación socioeconómica de la víctima y/o como un castigo del agente dañador (demandado).

\section{QUÉ SE ENTIENDE POR DAÑO MORAL}

La verdad es que, con el paso del tiempo y la aceptación jurisprudencial del daño moral desde el segundo decenio del siglo XX en Chile, se ha producido un incremento importante del ejercicio de acciones de responsabilidad que pretendenresarcir daños de orden extrapatrimonial, tanto en elámbito contractual como en el delictual. Las acciones de indemnización de perjuicios ejercidas por las víctimas en contra del autor del daño o del deudor (según los casos), tienen como base la vulneración de cierto tipo de derechos, intereses o bienes jurídicos que les permite su resarcimiento. Esto se ha generado por la constante evolución del concepto de "daño moral", tomando distintos nombres, y que puede ser categorizado en diversas especies de perjuicios extrapatrimoniales. ${ }^{9}$ En tal sentido la doctrina y, particularmente, la jurisprudencia entendió que el daño moral consistía en lo que hasta hoy conocemos como pretium doloris (el precio del dolor). ${ }^{10}$ No obstante, hay autores que señalan que el concepto de

9 En este sentido daño moral puede referirse a otros tipos específicos de perjuicios que se encuentran dentro de dos grandes categorías que son los perjuicios resultantes del daño corporal (dolor físico, aflicciones puramente mentales, daño sicológico, etc.) y otros que derivan de la lesión del gusto de vivir, como el perjuicio estético, sexual, familiar o de realizar ciertas actividades placenteras. Véase Barros Bourie, cit. (n. 4), p. 290. En el mismo sentido puede consultarse sentencia de la Corte de Apelaciones de Concepción, de fecha 10 de marzo de 2017, que en su considerando decimoctavo señala que "el daño moral puede ser entendido como aquel de carácter extrapatrimonial, que responde a la lesión de intereses valiosos para la víctima y que, por tanto, ameritan su indemnización. Este daño presenta distintas facetas comenzando por el daño corporal, que se traduce en el dolor producido por las lesiones corporales, que producen naturalmente una aflicción física o moral, así como también por el temor o afectación que produce en la víctima el acto constitutivo de la lesión". Corte de Apelaciones de Concepción, 10 de marzo de 2017, Identificador Thomson Reuters CL/JUR/821/2017.

${ }^{10}$ Ya en una de las primeras sentencias en Chile, una de ellas dictada por la Corte de Apelaciones de Santiago, de fecha 27 de julio de 1907, que hace referencia a los daños a bienes no patrimoniales, se expresa que esta clase de perjuicios se relacionan directamente con el dolor o sufrimiento que padece la víctima del ilícito (en este caso del padre del menor fallecido). Corte de Apelaciones de Santiago, 27 de julio de 1907, Identificador Thomson Reuters CL/JUR/3/1907. V. Corte Suprema, 27 de marzo de 2002, Rol 1634-2001 ("Estarda con Moraga y Márquez"), Identificador Thomson Reuters CL/ JUR/2494/2002. En el considerando $11^{\circ}$, la Corte define el daño moral señalando que "nuestros tribunales en lo que se refiere al daño moral han seguido una de las tesis más clásicas como pretium doloris que afecta a la integridad espiritual de una persona, el que es apreciado por el juez de acuerdo 
daño moral es mucho más amplio ${ }^{11}$ y que más bien la categoría pretium doloris constituye la especie del género "daño extrapatrimonial". ${ }^{12}$

Alessandri, por su parte, en su célebre obra sobre responsabilidad extracontractual, define el daño moral como "dolor, pesar o molestia que sufre una persona en su sensibilidad fisica o en sus sentimientos, creencias $o$ afectos" ${ }^{13}$ Esta definición lleva de por sí la subjetividad del individuo, entregando en manos de la víctima la determinación de la existencia del daño, concepto que es compartido por la jurisprudencia en cuanto también lo define como "sufrimiento, dolor, o molestia que el hecho ilícito ocasiona en la sensibilidad física o en los sentimientos o afectos de una persona, lo que constituye una apreciación subjetiva que queda entregada sólo al criterio y discernimiento de aquéllos, valoración que no acepta revisión de este tribunal, por la vía de la casación en el fondo". ${ }^{14}$

La conceptuación de esta clase de perjuicio resulta -por consiguienteproblemática desde su inicio. Primero por la constante evolución de esta categoría en el derecho de contratos y, desde luego, en el derecho de daños. ${ }^{15}$ Segundo porque es un concepto lleno de subjetividad, al menos en su apreciación e incluso en la indicación de algunos daños específicos, de manera que tanto su configuración y prueba pueden adolecer de cierto control tanto por la víctima en su existencia, y por el juez en el estándar de prueba exigido para lograr la convicción que permita su resarcimiento.

\footnotetext{
a los antecedentes del proceso y la equidad".

${ }^{11}$ BArros Bourie, cit. (n. 4), p. 230. En estas líneas el autor señala que: "Más preciso es el concepto de daños no patrimoniales, que el uso ha subsumido bajo la denominación común de daño moral. Lo cierto es que el término daño moral tiende a oscurecer la pregunta por el tipo de daños a que se hace referencia". En España pueden mencionarse, por ejemplo, Martin-CASAls, Miquel; Ribot, Jordi; SolÉ, Joseph, "El daño moral", en Cámara, Sergio (coord.), Derecho Privado Europeo, Colex, Madrid, 2003, p. 858, señalan que "daño moral es el perjuicio que experimenta una persona y que no afecta a su patrimonio, ni a sus ingresos, ni puede cuantificarse económicamente con referencia a un valor de mercado"; DiEz-PICAzo sostiene que "nos inclinamos por entender que el denominado daño moral debe reducirse al sufrimiento o perturbación de carácter psicofísico en el ámbito de la persona, sin proceder al respecto a concepciones extensivas, en las que la indemnización carece de justificación. Aun concebido en los estrictos términos que se acaban de esbozar, no todo sufrimiento psicofísico engendra un daño moral indemnizable, sino (...), aquel que es consecuencia de lesiones de derechos de la personalidad". Véase Diez-Picazo, cit. (n. 3), p. 328.

${ }^{12}$ Barrientos Zamorano, Marcelo, "Del daño moral al daño extrapatrimonial: la superación del pretium doloris" Revista Chilena de Derecho, 2008, Vol. 35 N 1, p. 90.

${ }^{13}$ Alessandri Rodríguez, Arturo, De la responsabilidad extracontractual en el Derecho Civil Chileno, Imprenta Universitaria, Santiago, 1943, p. 220.

${ }^{14}$ V. Corte Suprema, 7 de enero de 2003, Identificador Thomson Reuters CL/JUR/3247/2003; especialmente su considerando $8^{\circ}$.

${ }^{15}$ Diez-Picazo, cit. (n. 3), pp. 239-240.
} 
De ahí entonces que podemos dilucidar dos aspectos importantes en el contexto de la conceptuación del daño moral. El primero, tal como se señaló, consiste en el dominio del perjuicio reclamable por parte de la víctima. Desde este punto de vista, es complejo poder establecer una vara que mida e identifique objetiva e igualitariamente los daños que por su naturaleza no lo son, v. g. el daño moral. Sin embargo, la comentada subjetividad puede generar una distorsión del concepto de perjuicio extrapatrimonial en el sentido de querer incorporar cualquier afectación fuera de lo patrimonial sin limitaciones.

\section{Interés protegido}

Dada la realidad jurisprudencial que impera en la actualidad, se sabe que respecto de un interés o derecho extrapatrimonial protegido, la víctima de un ilícito no tiene mayores inconvenientes en solicitar una compensación en dinero cuando éste ha sido vulnerado, a causa de la amplitud del concepto y la textura abierta con que los tribunales circunscriben este perjuicio. ${ }^{16}$

En un plano colectivo, cuando se trata de ciertos derechos o intereses, la sociedad toda entiende que siempre hay un daño moral jurídicamente resarcible. Por ejemplo, cuando el bien afectado es la vida, la integridad física, la salud, la integridad psíquica u otros de similar naturaleza. Estos bienes jurídicos realmente no tienen valor económico, pero la víctima se encuentra en la necesidad de asignarle uno para efectos de ejercer la acción indemnizatoria, y lo hace de manera subjetiva, dependiendo de muchos factores; entre ellos se encuentran los sociales, laborales, económicos, etc. En este sentido, se produce un cierto reconocimiento de que hay daño moral (a priori) cuando los bienes o intereses afectados son los que corresponden a derechos fundamentales que se refieren al cuerpo y psiquis de una persona. ${ }^{17}$

${ }^{16}$ Por ejemplo una sentencia de la Corte de Apelaciones de Concepción define, aunque en el plano del derecho del consumo, lo que entiende por daño moral en el considerando $11^{\circ}$ : “( ...) el daño moral es todo menoscabo o detrimento no patrimonial que afecta la integridad psíquica del individuo, como la alteración en la tranquilidad de espíritu, molestias personales, inversión de tiempo en la solución de un problema, no cumpliendo de expectativas ofrecidas, impotencia, frustración o enojo a causa de un mal servicio" (énfasis añadido). Como puede notarse, se trata de un concepto abierto, cuya expresión en palabras subyace una idea general de afectación del individuo sin limitar en ningún caso las condiciones en que debe operar, ni los requisitos que deben darse para considerarlo un daño jurídicamente resarcible. (Identificador Thomson Reuters CL/JUR/2030/2013).

${ }^{17}$ De hecho, esta idea ha sido instrumentada para justificar el resarcimiento del daño moral tanto en sede extracontractual como contractual, ya que las garantías establecidas en el artículo 19 de la Constitución impregnan la relación entre los agentes, llegando incluso a la relación convencional. Véase Domínguez Hidalgo, Carmen, "La reparación del daño moral derivado del contrato en el derecho civil 
Frente a aquellas vulneraciones y por la extensión que ha tenido el concepto de daño moral, existen otro tipo de intereses o derechos que no han tenido el mismo impacto social, y en donde la subjetividad se deja ver en su mayor esplendor. Se trata por ejemplo de lo que la jurisprudencia denomina como "molestias", "pesar" "disgusto" u otros términos de similar connotación 18 que se analizan desde dos aristas: derecho de contratos y derecho de daños.

\section{a) Derecho de contratos}

Claramente, no todos aceptan que las meras molestias por algún hecho son necesariamente constitutivas de daño moral, ya que naturalmente podrían no serlo. ${ }^{19}$ La problemática sobre este asunto ha sido desarrollada mayormente en el ámbito de la responsabilidad contractual, en donde juegan un rol importante las nociones de causalidad, previsibilidad y el mismo daño moral. Esto se produce por la inquietante discusión acerca de si los contratos con contenido exclusivamente pecuniario pueden engendrar - una vez acaecido su incumplimiento- un daño moral jurídicamente resarcible y, como categoría específica, la aceptación de las denominadas molestias o disgustos por el incumplimiento. La verdad es que después de una larga discusión, ${ }^{20}$ que tuvo

chileno: realidad y límites”, en De la Maza G., I. (Director), Cuaderno de Análisis Jurídico III. Temas de Contratos, Fundación Fernando Fueyo, Santiago, 2006, pp. 231-232.

${ }^{18}$ Ver nota 16.

${ }^{19}$ Carmen Domínguez Hidalgo estima que la molestia o perturbación que genera, por ejemplo, el incumplimiento de contrato no puede ser constitutivo de daño moral. Esto porque tal situación (incumplimiento) forma parte de los posibles riesgos que pueden materializarse en el ámbito de la contratación. Por lo que llegar a establecer una conceptuación de daño moral como molestias suena, al menos, excesivo. La autora se refiere a la materia del siguiente modo: "En primer lugar, la infracción de contrato siempre supone molestias y desagrados al acreedor. Es evidente, teniendo presente que, si el acreedor había consentido en el contrato, era porque tenía un interés en la prestación prometida por el deudor, el que por efecto del incumplimiento resulta afectado. De este modo, ante todo incumplimiento contractual cabe invocar perturbaciones y molestias. Sin embargo, no debe ser confundido con el daño moral derivado de contrato, pues de ser así habría que concluir, lisa y llanamente, que todo incumplimiento contractual lo genera, lo cual, indiscutiblemente, es un exceso. Una conclusión como ésa sólo generaría un desprestigio inmediato de una partida resarcitoria que tanto ha costado acoger entre nosotros y que tanto puede hacer en la tutela personal". Véase Domínguez Hidalgo, cit. (n. 17), pp. 236-237. Otros autores también han cuestionado la conceptuación que ha recibido el daño moral y la aplicación del mismo en el ámbito judicial, identificando cierta distorsión en la utilización de esta institución en el derecho de daños. Véase Diez-PICAzo, Luis, El escándalo del daño moral, Civitas, Madrid, 2008.

${ }^{20}$ Existiendo por un lado una antigua doctrina que rechazaba la producción de perjuicios morales en el ámbito contractual, tales como BUTRÓN FIRPO, Roberto, "La indemnización del daño moral en nuestra legislación" en Tavolari, Raúl (Dir.) Doctrinas Esenciales Derecho Civil. Responsabilidad Extracontractual, Editorial Puntolex, Santiago, 2009, p. 146; BARros Errázuriz, Alfredo Curso de Derecho Civil. Segundo Año, Editorial Nascimiento, Santiago, 1932, p. 89; Alessandri RodríGuez, cit. (n. 13), p. 547. Y otros que se inclinan por la aceptación de esta partida indemnizatoria en este 
lugar durante la segunda mitad del siglo XX en nuestro país, la jurisprudencia se encuentra totalmente conteste respecto de la procedencia de esta partida indemnizatoria en el derecho de contratos. No obstante, el problema persiste ya no desde la óptica de la "procedencia" sino más bien de la conceptuación del perjuicio reparable y su delimitación.

Al día de hoy y después de un número significativo de fallos, ${ }^{21}$ la jurisprudencia -además de aceptar de forma general la indemnización de los daños extrapatrimoniales en el ámbito contractual- ha realizado un intento de conceptuación que parece serun tanto extensivo y poco trabajado en sus contornos y límites. Muchos de ellos se refieren a las molestias por incumplimiento como fuente de indemnización. Quizá el término molestias no es el que presenta la distorsión, sino la falta de especificación de las circunstancias concretas sobre las cuales se desarrolla el incumplimiento, es decir, cómo aquello afecta a la víctima y en qué grado. Todas estas circunstancias carecen, pues, de una calificación judicial que impide delimitar correctamente lo que es daño moral.

Ciertamente los tribunales de justicia intentan dar aplicación absoluta al principio de reparación integral del daño (en favor de la víctima), principio que se relaciona con un imperativo constitucional vigente en nuestro ordenamiento (protección de la integridad psíquica y física del individuo). No obstante, considero que aquella máxima está sujeta a condiciones que la hagan viable

terreno, Gatica Pacheco, Sergio, Aspectos de la indemnización de perjuicios por incumplimiento de contrato, Editorial Jurídica de Chile, Santiago, 1959, pp. 150 y ss., FuEYo LANERI, Fernando, "Sobre el daño extrapatrimonial en el incumplimiento de contrato", Revista Jurídica de Buenos Aires, 1965, p. 72. Asimismo, en otro trabajo editado en aquellos años Fueyo LANERI, Fernando, "De nuevo sobre el daño extrapatrimonial en el cumplimiento de contrato", Colección Justitia et Jus, Sección de Investigaciones, $\mathrm{N}^{\circ}$ 8, 1972, p. 26; TOMASEllo HART, Leslie, El daño moral en la responsabilidad contractual, Editorial Jurídica de Chile, Santiago, 1969, pp. 49 y ss. Un análisis sobre el daño moral de la misma época puede consultarse en BALTIERRA, Enrique, Indemnización del daño moral en la legislación civil chilena, Memoria de Prueba, Universidad de Chile, 1956, p. 72. Por su parte la evolución de la doctrina en el estudio de este tema se dejó ver con bastante fuerza a fines del siglo pasado y comienzos de éste, Domínguez Águila, Ramón; Domínguez Benavente, Ramón, "Daño moral en la responsabilidad contractual. Ausencia de una norma excluyente de reparación", Revista de Derecho Universidad de Concepción, 1994, No 196, pp. 155-160; Cárdenas Villarreal, Hugo, "Sobre la extensión de la reparación del daño moral derivado de contrato", Revista Chilena de Derecho, vol. 31 N 2, 2004, pp. 379-387; CÁrdenas Villarreal, Hugo, "Daño moral por incumplimiento de contrato", Revista Chilena de Derecho, Vol. 33, No 3, 2006, pp. 585-593; Domínguez Hidalgo, cit. (n. 17), pp. 231-232.

${ }^{21}$ Corte de Apelaciones de Concepción, 10 de marzo de 2006 (considerando $6^{\circ}$ ), acción de indemnización de perjuicios, identificador Thomson Reuters CL/JUR/4614/2006; Corte Suprema, 11 de abril de 2007, acción de indemnización de perjuicios, identificador Thomson Reuters CL/JUR/546/2007; Corte Suprema, 7 de enero de 2009, Rol 5814-2007 (considerando $6^{\circ}$ ), acción de indemnización de perjuicios. Identificador Thomson Reuters CL/JUR/779/2009; Corte Suprema, 26 de enero de 2009, acción de indemnización de perjuicios, identificador Thomson Reuters CL/JUR/9389/2009; Corte de Apelaciones de Punta Arenas, 23 de septiembre de 2016, acción de indemnización de perjuicios, identificador Thomson Reuters CL/JUR/6682/2016. Todas estas sentencias conceptúan al daño moral como "molestias". 
en la práctica, y de eso dependen las circunstancias concretas sobre las que se ha desarrollado el contrato, el incumplimiento y el daño, de modo que dichos elementos funcionen como factores que iluminen el razonamiento judicial y la adjudicación de los derechos y obligaciones entre las partes litigantes.

\section{b) Derecho de daños}

Luego, en el ámbito de la responsabilidad extracontractual, el daño moral probablemente no sufra importantes modificaciones conceptuales, ya que los daños se refieren generalmente a la integridad física y psíquica de la persona, siendo el problema transversal, el abuso de la discreción que tiene el juzgador para determinar una indemnización que, por argumentos distintos a la equidad, ${ }^{22}$ en algunos casos no podría otorgar.

De acuerdo con esta idea, cuando se está en presencia de daños o vulneraciones de bienes jurídicos que por su importancia le interesan a la sociedad toda, el daño moral es evidente y casi indiscutible, adoptando cierto carácter de objetividad. ${ }^{23}$ Luego, cuando el perjuicio se refiere a molestias, zozobras, frustración, disgusto, etc., es complejo afirmar si realmente se está en presencia de un daño moral jurídicamente resarcible, pero no solamente por su tenor, sino más bien por su utilización excesivamente discrecional por los tribunales de justicia, sin limitaciones y sin fundamentos sólidos. Esta situación se produce porque no se han delimitado los contornos jurídicos del daño moral, sino que sólo se ha establecido un concepto abierto, amplio, que lleva muchas veces a ser fuente de lucro más que el reclamo de una injusticia, lo cual no es el espíritu del derecho de daños. ${ }^{24}$

La dogmática civil chilena ha reconocido algunos conceptos de daño moral que se basan principalmente en la evolución de la jurisprudencia respecto de esta institución. ${ }^{25}$ En ellos se ve un concepto siempre subjetivo, enraizado en

\footnotetext{
${ }^{22} \mathrm{E}$ incluso en algunos casos, se otorga la indemnización recurriendo a consideraciones punitivas que van incluidas implícitamente en ella. Diez Picazo, cit. (n. 3), p. 240.

${ }^{23}$ Domínguez Hidalgo, Carmen, "El daño moral en Chile: Contornos y problemas", Revista Anales Derecho UC, número 1, Editorial Legis, Santiago, 2006, pp. 307-328.

${ }^{24}$ LINACERO DE LA FUENTE se muestra contraria a aceptar que las molestias puedan ser constitutivas del daño moral, y señala que: "En dicho sentido, la investigación del concepto de daño moral exige una labor previa y rigurosa de delimitación de dicha categoría jurídica que debe excluir, en principio, la identificación del daño moral con el elenco de molestias, frustraciones, malestares, contrariedades, disgustos o zozobras, de mayor o menor intensidad, que-lamentable pero inevitablemente-acompañan al ser humano a lo largo de su existencia". Véase Linacero de la Fuente, María "Concepto y límites del daño moral: el retorno al pretium doloris", Revista Crítica de Derecho Inmobiliario, 2010, No 720 , p. 1560 .

${ }^{25}$ Alessandri Rodríguez, cit. (n. 13), p. 220; Diez Schwerter, José Luis, El daño extracontractual, Editorial Jurídica de Chile, Santiago, 2012, p. 82. En estas páginas el autor se refiere al concepto de
} 
diversos valores sobre la dignidad e integridad del ser humano con un intento de justificación. No obstante, dichas definiciones abiertas sólo han generado un debate que ha devenido en la utilización excesivamente discrecional de esta institución y que siguen teniendo vigencia en la jurisprudencia más respetada de nuestro país, dejando abierta la puerta para el aumento progresivo de "molestias" y "disgustos" que pueden estar lejos de constituir un daño jurídicamente resarcible.

Por consiguiente, considero que los bienes o intereses de la víctima y el posterior daño de los mismos pueden ser delimitados si la interacción dañosa se estructura sobre la base de criterios de justicia distributiva que determinen aquello que puede ser reclamable y que una vez definido aquello, se puede pasar a la etapa de rectificación mediante la indemnización.

\section{DELIMITACIÓN DEL DAÑO MORAL Y JUSTICIA DISTRIBUTIVA}

La dogmática civil tradicional se ha preocupado fuertemente respecto de qué es daño moral, es decir qué cuenta como un daño moral jurídicamente resarcible. De acuerdo con esta afirmación, existe una motivación de índole conceptual para intentar llegar a la esencia de esta institución y posteriormente encontrar su justificación. No obstante, respecto de la justificación de esta partida indemnizatoria no se han articulado trabajos, en el medio nacional, que expliquen por qué ante la vulneración de un derecho como la integridad física o psíquica, se siga para el autor la consecuencia de tener que indemnizar dicho daño.

Esto último, como recién dije, tiene que ver con la justificación de la indemnización de perjuicios más allá de la conceptuación concreta de daño moral (o extrapatrimonial) que pueda ser aceptada por los operadores jurídicos. Ante esto, entonces, el problema del daño moral es doblemente complejo. Primero, porque el concepto - tal como se señaló más arriba- es subjetivo y entregado a la víctima y el juez; y segundo, porque no están expresados de manera clara los argumentos que den cuentan de la justificación del resarcimiento de esta clase de perjuicio.

daño moral más generalmente conocido por la jurisprudencia, consistente en el denominado pretium doloris; Por todos, Domínguez Hidalgo, Carmen, El daño moral, Editorial Jurídica de Chile, Santiago, 2000 , pp. 51-66. Que se refiere a las concepciones negativas y positivas del daño moral. En las primeras se comprenden las definiciones del daño moral como: a) daño moral es todo perjuicio cuyo objeto no es un interés patrimonial; b) daño moral es todo daño que no repercute en el patrimonio; c) daño moral es todo daño que carece de equivalencia pecuniaria. En cambio, las concepciones positivas a que la autora se refiere son: a) daño moral como pretium doloris; b) daño moral como menoscabo de un derecho extrapatrimonial; c) daño moral como menoscabo a los bienes de la personalidad; d) consideración del carácter no patrimonial del interés lesionado. 
A partir de ahora intentaré mostrar una posible respuesta a estos dos problemas. Primero, mediante un ejercicio de delimitación del daño moral sobre la base de sus requisitos, para luego referirme a los aspectos de justicia distributiva que pueden incidir en su justificación o, al menos, en la asignación de derechos en un ámbito colectivo (público) y luego su adjudicación específica en un litigio privado (demandante-demandado).

\section{Entidad del daño moral y riesgos}

En términos generales, hablar de "daño" o de "perjuicio" puede suponer varios sentidos permitidos y aceptados socialmente. Entre dichos sentidos existen algunos que se refieren a una afectación (moral) de una persona, producida en el desarrollo normal de la convivencia en una comunidad y que dentro de ciertos márgenes y umbrales resultan ser imperativamente tolerables por quien la sufre. ${ }^{26}$

Los conceptos como "zozobra", "disgusto", "frustración", “congoja" o "molestia" son términos que a diario una persona debe enfrentar cuando desarrolla su vida en una sociedad civil organizada, en el que constantemente interactúan diversos intereses muchas veces contrapuestos entre sí, y que pueden dar lugar a muchas formas específicas de daño y en distintos grados. Luego, el derecho como orden normativo si bien protege ciertos intereses, no lo hace respecto de todos. No es posible pretender que todas las afectaciones a una persona (que se traduzcan en un cierto tipo de "daño moral") sean objeto de protección jurídica, ya que distorsionaría severamente la comprensión que tenemos sobre el derecho como un instrumento que sirve para la protección de intereses, que son seleccionados a través del proceso de reconocimiento normativo y/o de principios, en los que si bien se encuentran aquellos que velan por la protección integral de la persona humana, siempre debe entenderse en un contexto razonable y no desmedido, de manera que permita trazar un límite entre lo no relevante y lo jurídicamente importante. ${ }^{27}$

\footnotetext{
${ }^{26}$ Diez-Picazo, cit. (n. 19), pp. 52-53; Linacero de la Fuente, cit. (n. 24), p. 1578.

${ }^{27}$ En Chile el profesor Enrique BARros ha señalado que la noción de daño, a lo menos en términos más normativos, se refiere a una cuestión excepcional para ser considerado resarcible. Él señala que un requisito del daño es que sea "significativo" y luego que: "La noción de daño excluye las incomodidades o molestias que las personas se causan recíprocamente como consecuencia normal de la vida en común. Los beneficios de la vida en sociedad exigen inevitablemente ciertos grados recíprocos de tolerancia respecto de las turbaciones provocadas por los demás. Por eso no toda turbación da lugar a reparación. En definitiva, el daño sólo da lugar a responsabilidad civil si es significativo o anormal". BARRos BourIE, cit. (n. 4), p. 226. En el mismo sentido el profesor Corral señala que: "Aunque en general se suele enfatizar el principio de la reparación integral que impone que "todo" daño debe ser indemnizado, lo
} 
Seguidamente, sufrir aflicciones o molestias por algún hecho no implica necesariamente un juicio de valor sobre la conducta del agente dañador, ya que dicha consecuencia puede haber sido resultado del ejercicio legítimo de un derecho, de una autoridad o del desarrollo de la vida en sociedad. Por eso tanto el deber de no dañar ${ }^{28}$ como el principio de reparación integral del daño deben entenderse dentro de los límites de las interacciones sociales entre los agentes, excluyendo daños de bagatela u otros sin una significación jurídica que lleve a su indemnización.

Es en este sentido, por consiguiente, en el que se erige la limitación del daño moral para su resarcimiento en el derecho de daños. Desde luego, esto tiene que ver con criterios de justicia distributiva, porque en cierto modo definen o determinan qué es aquello que será indemnizado. Dicho de otra manera, se definen distributivamente los derechos o intereses que serán admitidos como base para una reclamación y a su vez se excluyen los que, al menos, no tendrán valor jurídico. Es decir, define los límites de la libertad de acción de los posibles agentes dañadores frente a la seguridad de las posibles víctimas.

Esta idea es relevante para comprender la estructura del derecho de daños y la forma en cómo interactúan los diversos agentes. Yo adhiero a la idea de que el derecho de daños posee una estructura bipartita: ${ }^{29}$ se identifica una instancia previa, colectiva $\mathrm{y}$, en algún sentido, pública que se refiere a cuestiones de justicia distributiva y en donde se asignan ciertos derechos y deberes a todo el grupo social organizado. Esos derechos y deberes que se asignan son los que el profesor Diego Papayannis denomina como "derechos y deberes de indemnidad"30 (idea a la cual también suscribo). Una vez definidos -en la etapa distributiva- los derechos y deberes de las partes, se puede identificar quién debe qué y a quién, es decir, quién debe ejecutar o abstenerse de una determinada acción, quien tiene el deber de

cierto es que si las personas reclamaran por todos los daños que sufren en su diario relacionarse con los demás, el sistema judicial colapsaría. Parece lógico en consecuencia que el "todo" daño se refiere a un daño que tenga una entidad mínima proporcionada a la actividad que deberá desplegarse para obtener su reparación. Dicho de otra manera, la convivencia social y una cierta solidaridad comunitaria nos lleva necesariamente a tolerarnos unos a otros perjuicios y molestias que no alcanzan a lesionar nuestros intereses de un modo que merezca reclamar la reacción del derecho [...]". Véase CoRRAL TALCIANI, Hernán, Lecciones de responsabilidad civil extracontractual, LegalPublishing, Santiago, 2013, pp. 140-141.

${ }^{28}$ En la defensa de la existencia de un deber de no dañar, frente a un derecho correlativo de la víctima a no ser dañada, puede verse PAPAYANNIS, cit. (n. 1), p. 144 y ss.

${ }^{29}$ Papayannis, cit. (n. 1), p. 271 y ss.

${ }^{30}$ Papayannis, cit. (n. 1), p. 318 y ss. 
cuidado o debe tomar a su cargo el coste de las medidas precautorias, etc. ${ }^{31}$ Finalmente determinar la rectificación del daño a través de un mecanismo de justicia privada consistente en la justicia correctiva. Principio de justicia que se encarga de la rectificación del injusto, pero ya de manera directa y relacional. ${ }^{32}$

Por otra parte, y volviendo a la discusión sobre la no resarcibilidad de ciertas molestias y zozobras propias de la vida en sociedad, es relevante entonces hacerse cargo de responder la primera interrogante relativa a la delimitación del daño moral.

Ciertamente el daño moral está sujeto a las condiciones exigidas para todo daño que lo permita ser considerado como un perjuicio jurídicamente relevante y por lo tanto indemnizable. No obstante, la situación suele ser distinta si el daño es reclamado por incumplimiento contractual o por responsabilidad extracontractual.

\section{Delimitación del daño moral contractual}

Respecto del daño moral contractual, la argumentación se articula normalmente sobre la base de dos elementos: previsibilidad y la entidad del daño. ${ }^{33}$

Una sentencia de la Excma. Corte Suprema de fecha 1 de octubre de $2012,{ }^{34}$ que trata sobre el incumplimiento de contrato de custodia de vehículo

\footnotetext{
${ }^{31}$ Papayannis, Diego, El derecho privado como cuestión pública, Ediciones Universidad Externado de Colombia, Bogotá, 2016, pp. 216 y ss. De acuerdo al autor, los efectos distributivos del derecho de daños no solamente se ven refrendados por la determinación de los límites de la libertad de acción del potencial agente dañador frente a la seguridad de la posible víctima. También se ven reflejados, ciertamente, en el tipo de regla sobre la cual dichos agentes van a interactuar. Por ejemplo, no será lo mismo que haya una regla de a) no responsabilidad; b) responsabilidad por culpa o c) responsabilidad objetiva para el potencial agente dañador, pues cada regla determina las medidas precautorias que debe asumir la responsabilidad y, desde luego, determina el nivel riqueza o pobreza del mismo.

32 WeInRIB, La idea ..., cit. (n. 7), p. 96.

${ }^{33}$ Así se ha reconocido también en España, en el sentido de que la indemnización del daño moral derivado del incumplimiento contractual está, en algún sentido, basado en dos ideas centrales para conceptuarlo y delimitarlo. Rodríguez Guitián señala lo siguiente al respecto: "Tomando como punto de partida, pues, la adopción de un concepto amplio de daño moral, estimo conveniente señalar, al menos dos criterios, que permiten marcar ciertos límites a tal indemnización: por una parte, la aplicación del artículo 1107 del Código Civil (que se ocupa de la extensión del daño resarcible, delimitando, pues, los daños desde el punto de vista cuantitativo) y, por otra, la exigencia de que el daño moral sea de una cierta entidad." (énfasis añadido). Véase RodRíGuez GuITIÁN, Alma, "La reparación del daño moral en la contratación inmobiliaria" Revista de Derecho Universidad del Norte, 2008, No 30, pp. 156-157.

${ }^{34}$ Corte Suprema, 1 de octubre de 2012, Rol 4415-2010, Identificador Thomson Reuters CL/ JUR/2153/2012.
} 
(estacionamiento), desarrolla con gran inteligencia la procedencia de la indemnización del daño moral contractual, limitando el tema a la delimitación, es decir en qué casos procede y qué casos no cuando estamos frente a un contrato. El considerando $10^{\circ}$ de este fallo señala lo siguiente:

"DECIMO: Que estima este tribunal de casación que para analizar la procedencia del daño moral por la infracción de un contrato, no es suficiente, para descartarlo, la mera constatación de que la convención, por su naturaleza, no protege intereses extrapatrimoniales o comprende intereses que claramente pueden afectar a la personalidad del sujeto, sino que es menester detenerse en las particulares circunstancias y características en que se celebró el que vincula a las partes, pues de ellas fluirá la posibilidad de que la mencionada infracción provoque un daño extrapatrimonial".

De la lectura de este considerando se infiere que el contenido prestacional de un contrato no determina anticipadamente los daños extrapatrimoniales resarcibles, sino que se debe atender a las circunstancias particulares y características del mismo, en virtud de las cuales se podrá deducir si el incumplimiento contractual ha de generar un daño moral.

Posteriormente señala en el considerando undécimo, lo siguiente: "Tampoco cabe desconocer que para la contraparte de quien contrata la custodia del vehículo es plenamente previsible suponer que el deterioro o robo en éste, que configura el incumplimiento de obligación, va a causar la molestia o aflicción que antes se mencionaba".

Finalmente, la Corte indica en el considerando duodécimo:

"DUODECIMO: Que por las consideraciones que anteceden, estima esta Corte Suprema que en el contrato especifico a que se ha hecho referencia, el incumplimiento de la obligación contraída por la sociedad concesionaria era idóneo para provocar daños patrimoniales y extrapatrimoniales, siendo menester concluir, en relación con estos últimos, que procede su indemnización toda vez que el incumplimiento era imputable a culpa de dich a concesionaria, que el deudor se encuentra en mora, que la ocurrencia de los mismos era previsible al tiempo de contratar y que surgen como consecuencia inmediata y directa de tal infracción, lo que permite atribuirle las calidades de daños previstos y directos, respectivamente." (Énfasis nuestro).

El análisis de la Corte Suprema en este aspecto resulta importante, toda vez que la acción indemnizatoria que abarca el daño moral no dependerá de la naturaleza o contenido de la prestación contractual. Es decir, la acción de 
indemnización de perjuicios por daños extrapatrimoniales no está subordinada al contenido prestacional del contrato, por lo que, al margen de si este protege intereses de carácter patrimonial o extrapatrimonial, pero resultan previsibles para el deudor aplicando un criterio de razonabilidad, deberán ser indemnizados.

No obstante existir un razonamiento pro víctima que permite a la Corte Suprema concluir que prácticamente todos los incumplimientos generan daño moral -dada la amplia conceptuación de éste-y que además en todos los contratos sería medianamente previsible la ocurrencia de un perjuicio extrapatrimonial, igualmente -esta solución- no está lejos de generar serios cuestionamientos a nivel de la función del contrato y la protección de los intereses de las partes.

Así, en el mismo fallo se generaron 2 votos disidentes que contrarían la postura acordada por la sala de la Corte. En este sentido, la Sra. Ministra Maggi y el abogado integrante Sr. Prado indican que, si bien la procedencia de la indemnización del daño moral por incumplimiento contractual es un tema que no se discute, éste no procede de forma absoluta "...pues la naturaleza y el tipo especifico de contrato serán relevantes a la hora de determinar si el menoscabo moral que se pretende derivado del incumplimiento de una obligación determinada resultaba o no previsible para los contratantes, es decir, si el acreedor de la indemnización que se demanda tomó a su cargo el riesgo de lesionar intereses extrapatrimoniales de su contraparte" (Considerando $2^{\circ}$ ). Luego agregan que la previsibilidad en materia de daño moral contractual puede tener dos fuentes, la primera relativa a la naturaleza de la obligación contraída, en la medida que se refiera a intereses extrapatrimoniales; y la segunda, a las circunstancias que rodean la celebración del contrato. ${ }^{35}$

Por lo anteriormente expuesto conviene, entonces, detenerse en dos aspectos que resultan relevantes para determinar el rol que cumple la previsibilidad en materia contractual, especialmente tratándose de daños extrapatrimoniales y concluir finalmente si esta clase de perjuicios procede en todo contrato, o bien sólo en algunos.

\section{a) La función del contrato}

En lo que respecta al contrato como mecanismo de colaboración social,

\footnotetext{
${ }^{35}$ Así, el voto disidente plantea la cuestión en los siguientes términos: "La previsibilidad del daño podrá provenir de la propia naturaleza de la obligación contraída, si ella está directamente vinculada con intereses extrapecuniarios, o de las circunstancias que rodean la celebración del contrato si estas conducen natural y razonablemente a suponer que el incumplimiento contractual acarreará consecuencias de orden extrapatrimonial" (Considerando $4^{\circ}$, énfasis añadido). Corte Suprema, 1 de octubre de 2012, cit. (n. 34).
} 
éste ha sido conceptuado y tratado desde los albores del Derecho Romano ${ }^{36}$ hasta nuestros días. En algún sentido, fue la codificación decimonónica la que recogió los principios inspiradores del derecho contractual que conocemos en la actualidad, no obstante existir nuevas doctrinas y postulados que dan cuenta de una nueva acepción de esta institución.

De esta forma, el contrato es un instrumento que puede cumplir variadas funciones, probablemente reconozcamos las que comúnmente suelen articularse en el mercado, como la transacción de bienes u objetos con valor comercial. Sin embargo, el contrato cumple un rol fundamental, que es de carácter económico y social, ${ }^{37}$ pero más específico, y quizá relevante, es la de satisfacer y proteger ciertos intereses. Tales intereses deben entenderse que han sido abstraídos por las partes, dotándolos de una carga normativa que permite su incorporación contractual y protección jurídica. Esto quiere decir que las partes, de alguna manera, han manifestado a la otra cuál es el interés principal que se encuentra en juego, y por lo tanto merecedor de mayor protección y satisfacción.

Con todo, en algunos contratos es casi evidente la manifestación del interés jurídico cautelado, como por ejemplo en los contratos médicos, que por su propia naturaleza permiten presumir que es la vida o la integridad física o psíquica la que es objeto del acuerdo y por lo tanto representa el bien sometido por el acreedor/paciente a la relación contractual. En otros casos, no es evidente, por lo que hay que recurrir a las reglas de la integración del contrato como es el caso del artículo 1546 del Código Civil o incluso a las circunstancias que rodean la celebración del mismo. Por lo anterior, conviene aclarar la situación desde la noción de la previsibilidad.

\section{b) La definición de previsibilidad}

Al parecer el problema de la indemnización del daño moral por incumplimiento contractual debe tener presente no solamente los intereses o bienes jurídicos que las partes han sometido a la relación contractual, porque la sola constatación de estos últimos no lo resuelve, sino que simplemente es un primer paso dentro del análisis. Así, verificados dichos intereses -al menos desde la óptica de la función del contrato y la interpretación del mismo-,

\footnotetext{
${ }^{36}$ En este sentido, en el sistema Gayano-Justinianeo se distinguen las obligaciones que nacen de los "contractus" y otros nacen de "ex delicto", teniendo el contrato una eminente calidad de acuerdo patrimonial entre dos partes. V. GuZmán Brito, Alejandro, Derecho Privado Romano, Editorial Jurídica de Chile, Santiago, 2012, p. 702.

${ }^{37}$ En este sentido López SAnta María, Jorge, Los Contratos. Parte General, LegalPublishing, Santiago, 2010, $5^{\text {a }}$ ed., pp. 6-11.
} 
hay que centrarse en la definición de previsibilidad, que es lo que finalmente importa a la hora de delimitar los perjuicios reclamables.

Si nos detenemos en el concepto de daño moral tampoco servirá de mucho, porque -de acuerdo a lo visto más arriba- la amplitud del concepto permitiría sostener que siempre es previsible el daño moral frente a un incumplimiento contractual (por la molestia, frustración, etc.), lo cual nos parece del todo excesivo.

Por este motivo analizar de mejor forma la previsibilidad podría aconsejar un mayor rigor para juzgar casos que pueden presentarse, inicialmente, como confusos. Creemos que, tal como lo ha planteado la jurisprudencia, la previsibilidad más allá de constituir una representación de los futuros daños que podría sufrir el acreedor a causa del incumplimiento, consiste en asumir determinados riesgos por parte del deudor. ${ }^{38}$ Es decir, prever significa determinar si el deudor tomó o no a su cargo la ocurrencia de determinados perjuicios, como lo serían los de carácter extrapatrimonial. ${ }^{39}$

Desde este punto de vista, y como ya lo ha dicho Pothier en su Tratado de las Obligaciones, prever implica asumir riesgos que están estrechamente ligados a la inejecución del contrato. Así, si el contrato posee un contenido totalmente patrimonial y ambas partes han negociado de buena fe sus cláusulas (hecho que se presume), se entiende que el deudor además de obligarse a la ejecución de la prestación, también lo ha hecho para la indemnización del daño que se derive de su incumplimiento, pero en este último término, sólo para aquellos daños o perjuicios que se deriven razonablemente de la inejecución

\footnotetext{
${ }^{38}$ Corte de Apelaciones de Concepción, 26 de junio de 2015, considerando $5^{\circ}$. Identificador Thomson Reuters CL/JUR/3600/2015. Esta sentencia señala lo siguiente: " $5^{\circ}$ ) Que, en términos generales la doctrina opina que siendo el contrato un medio destinado a la circulación y comercialización de bienes y servicios, su incumplimiento sólo afecta los intereses patrimoniales o económicos comprometidos en la respectiva negociación; siendo así, las consecuencias extra patrimoniales derivadas de la contravención y que afecten al contratante diligente, no son indemnizables al exceder el ámbito de los intereses cautelados por el contrato y los riesgos asumidos por el deudor al contratar". De acuerdo con este fallo, es posible concluir que no todo contrato cuyo contenido es eminentemente patrimonial lleva consigo la resarcibilidad de un daño moral, pues debe entenderse que el deudor sólo ha tomado el riesgo de soportar las consecuencias patrimoniales del incumplimiento, dando aplicación a la interpretación contractual y a la regla contenida en el artículo 1558 del Código Civil. En el mismo sentido, De la Maza Gazmuri, Iñigo, "Las cuentas corrientes y el dolor" en Mercurio Legal (7 de septiembre de 2016). Disponible en www.elmercurio.com/Legal/Noticias/Analisis-Juridico/2016/09/07/ Las-cuentas-corrientes-y-el-dolor.aspx

${ }^{39}$ Domínguez ha tomado una posición distinta y ha señalado que: "La extensión de la previsibilidad a los perjuicios extrapatrimoniales es posible si se tiene presente que el juicio de previsibilidad es uno de conocimiento en el sentido de que consiste en determinar los daños que, en el momento de la celebración del contrato, el deudor negligente pudo percibir que se derivarían del incumplimiento de la obligación a que se comprometía" (énfasis nuestro). Véase Domínguez Hidalgo, cit. (n. 17), p. 240.
} 
del contrato, y no cualquier daño ni mucho menos todos los daños, porque haría perder el sentido del límite establecido en el artículo 1558 del Código Civil, que es justamente una regla de causalidad y de limitación a los daños resarcibles. ${ }^{40}$

De esta forma, cuando se trate de contratos cuyo contenido prestacional sea principalmente patrimonial, como, por ejemplo, un contrato de cuenta corriente (casos que ya han sido planteados en la jurisprudencia), debe entenderse que el riesgo que el deudor ha asumido ante la inejecución es de naturaleza económica o patrimonial, por lo que la sola frustración, pesar o molestia por el no cumplimiento del contrato no puede contar como daño moral, salvo que de acuerdo a las circunstancias y haciendo un juicio de razonabilidad, pueda desprenderse que el deudor tomó a su cargo un riesgo o interés de carácter extrapatrimonial, de manera que permita su indemnización sin más controversia. Para ello se deberá acreditar que el riesgo de la ocurrencia daño moral solicitado en reparación ha sido incorporado al contrato expresa o tácitamente. En este último caso, mediante la aplicación del artículo 1546 del Código Civil; o por las concretas circunstancias que rodean la celebración de la convención. Adicionalmente, se deberá acreditar que dicho daño moral posee cierta entidad que lo convierta en un perjuicio jurídicamente resarcible..$^{41}$

Luego, tratándose de contratos cuyo contenido prestacional es de naturaleza extrapatrimonial, o bien tiene por objeto la satisfacción de un interés no apreciable en dinero, como el bienestar personal o el disfrute de determinados bienes, es razonable concluir que el deudor ha tomado como riesgo que, si no cumple el contrato, el daño consecutivo tendrá un contenido principalmente extrapatrimonial. ${ }^{42}$

Finalmente, creemos que el resarcimiento del daño moral por incumplimiento contractual debe ser sometido a una nueva revisión dogmática y jurisprudencial de manera que permita una mejor comprensión de esta institución que viene en crecida. Esto, según creemos, se puede lograr a través de 2 elementos claves. El primero es reformulando el concepto de daño moral, uno que si bien sea amplio - de manera que permita una extensa aplicación-, pero que también sea razonable para evitar abusos y situaciones injustas. En ese

\footnotetext{
${ }^{40}$ Véase Corral Talciani, Hernán, Contratos y daños por incumplimiento, Abeledo Perrot, Santiago, 2011, p. 180. El autor desarrolla y cita la idea planteada por Pothier en el Tratado de las Obligaciones.

${ }^{41}$ Domínguez Hidalgo, cit. (n. 17), p. 243. Tal como señala Domínguez, en los casos donde la obligación cuyo incumplimiento genere daños morales se encuentre tácitamente incorporada al contrato (sea por el artículo 1546 o por las circunstancias que rodean su celebración), se debe juzgar con especial rigor a la hora de delimitar los daños por medio de la previsibilidad "a fin de no transformar todo incumplimiento de contrato en una fuente de daños morales".
}

${ }^{42}$ Domínguez Hidalgo, cit. (n. 17), pp. 240-241. 
sentido, creemos que el daño moral contractual debe ser de cierta entidad cuando el contrato tenga un contenido prestacional patrimonial, de manera que el solo incumplimiento no siempre genere un daño extrapatrimonial (incumplimiento; molestias $\neq$ daño moral), ya que son dos cosas claramente distintas. ${ }^{43}$

En segundo lugar, consiste en establecer nuevos lineamientos para la aplicación de la previsibilidad como límite indemnizatorio, porque -según ha quedado expuesto con la jurisprudencia citada- es necesario tener una visión clara en cuanto a lo que significa prever y, sobre dicha base, limitar. Teniendo claro esto último será necesario advertir el tipo de relación contractual, su contenido prestacional y las circunstancias concretas que rodean su celebración.

\section{Delimitación del daño moral extracontractual}

Pero en cuanto a la segunda (que es la que nos interesa en este trabajo), al no existir relación convencional previa el análisis debiese detenerse al menos en la gravedad o entidad del perjuicio reclamado.

Si problema distributivo, es decir, de asignación de derechos y deberes (de indemnidad) consiste (desde cierta perspectiva) en trazar un margen que defina los límites de lo reclamable y lo no reclamable, o bien de lo jurídico respecto de lo meramente moral, basado en lo que he denominado "entidad" del daño moral, la pregunta que deviene necesaria realizar entonces es ¿cuándo un daño moral tiene cierta entidad que permita interponer una reclamación jurídica en el derecho de daños?

La respuesta a esta pregunta puede ser articulada desde dos perspectivas, siendo ligeramente residual la una de la otra y que se verán de acuerdo al siguiente apartado.

\section{a) Tipificación de intereses}

Una buena manera de resolver las dudas acerca de los derechos y deberes correlativos de los agentes que interactúan en una sociedad, es a través del proceso legislativo que delimite de forma clara las circunstancias constitutivas de la infracción del deber y el derecho afectado.

En la especie, la idea sería exigir del legislador que lleve al plano

\footnotetext{
${ }^{43}$ BARRos entiende que dentro del concepto de daño existe una noción de anormalidad en su producción. Es decir, el daño debe ser significativo o anormal, de modo que no cualquier tipo de molestia constituya un daño. Asimismo, indica que tratándose del daño moral el umbral permitido para que un mero perjuicio pase a ser un daño jurídicamente resarcible es mucho más complejo de determinar. Esto porque el daño moral está cargado de subjetividad y porque la tarea del juez en delimitar los contornos del daño extrapatrimonial es cada vez más difícil. Véase BARros BourIE, cit. (n. 4), p. 226.
} 
normativo (legal) la tipificación de ciertos intereses que puedan dar lugar a reparación, delineando sus contornos y formas. De este modo, si el trabajo legislativo resultara exitoso, a través de un estudio acucioso de los intereses sociales que cobran más relevancia, éste podría dar lugar a la confección final de un catálogo en el que se dé cuenta respecto de aquello que resulta valorado por la colectividad, fijando un piso mínimo sobre el cual erigir el umbral jurídico, excluyendo otras circunstancias análogas de menor envergadura.

Quizá este proceso implicaría exigir una tarea extremadamente detallista de la realidad social, teniendo en cuenta el constante dinamismo y confluencia de nuevos intereses, por lo que exigir una tarea de esta naturaleza, para algunos, puede sonar un tanto descabellada.

Por lo anterior, quizá la solución sea la intervención judicial de una manera más activa.

\section{b) El buen juez}

Tal como se dijo más arriba, quizá la tarea de tipificación de intereses de carácter extrapatrimonial que fijen el umbral mínimo sobre el cual la teoría jurídica de los daños resulte admisible, puede ser no solamente un arduo trabajo para aquel a quien se encomiende, sino que además podría resultar atentatorio a la tradición del sistema sobre el cual el libro IV del Código Civil ha estructurado los ilícitos civiles.

De acuerdo con el artículo 2314 del Código Civil: "El que ha cometido un delito o cuasidelito que ha inferido daño a otro, es obligado a la indemnización; sin perjuicio de la pena que le impongan las leyes por el delito o cuasidelito". De acuerdo con esta norma, queda en evidencia que el sistema sobre el cual se construye la responsabilidad extracontractual o derecho de daños, es a partir de una clausula abierta consistente en el deber de no dañar o alterum non laedere. Si esto es así, entonces basta la producción de un daño (en ciertas condiciones) para que tenga lugar la responsabilidad.

Esto no sucede por ejemplo en la legislación alemana que en el parágrafo 253 del BGB señala lo siguiente:

"Si por la lesión del cuerpo, la salud, la libertad o la autode-terminación sexual se ha de pagar restitución por daño, también se podrá solicitar indemnización equitativa en dinero por el daño no patrimonial si:

1. La lesión fue provocada dolosamente o

2. El daño no es irrelevante en consideración a su tipo y duración"

De acuerdo con este texto normativo, el daño moral derivado de un ilícito o Schmerzensgeld tiene una estructura de daños típicos, cuyos intereses reconocidos legalmente sólo dan lugar a reparación en los casos y condiciones 
que allí se señalan. Situación muy diversa a la que es nuestro sistema de daños.

Dado que la realidad jurídica de nuestro sistema impide tipificar algunos intereses, en cuanto considerarlos como daños resarcibles que impliquen un piso mínimo de juridicidad, entonces la tarea de determinar si realmente la víctima ha sufrido un daño moral resarcible debe quedar en manos del juez.

Inicialmente, la tarea judicial -dada la escasa interpretación de fondo respecto de las instituciones del derecho que impiden un progreso fluido en la jurisprudencia-, parece no ser el mejor periplo de esta empresa que resulta problemática desde sus pilares. No obstante, mi trabajo -en este sentido- no se limita a lo meramente descriptivo, sino más bien se dirige a lo valorativo y pretende sentar las bases para la delimitación judicial del daño moral.

De esta forma, si la tipificación de los intereses (especialmente los de naturaleza extrapatrimonial) no tiene lugar, o teniéndola, es defectuosa por ser muy general, el juez debe actuar como "un buen juez". Esto significa que las alegaciones de la víctima respecto de lo que ella considera como un daño han de ser tomados en cuenta junto a todos los otros antecedentes y circunstancias en torno a los cuales el hecho "dañoso" ha tenido lugar. ${ }^{44}$ De hecho, con ayuda o no de la citada tipificación, el buen juez debe interiorizarse no solamente en litigio privado sin más, sino que adicionalmente debe inmiscuirse en aquello que lo informe sobre la situación de la sociedad actual, aplicando criterios de tiempo y lugar.

Esto quiere decir que, de acuerdo a las condiciones y circunstancias sociales en un tiempo y lugar determinados, el juez -aplicando el criterio de lo razonable o del "buen juez"- será quien debe determinar si aquello que la víctima reclama como daño (moral) posee cierta entidad que permita considerarlo como una lesión grave y por lo tanto indemnizable. ${ }^{45}$

\footnotetext{
${ }^{44}$ La jurisprudencia ya ha conocido los diversos factores que inciden en la apreciación del daño moral, pero dirigen su mirada en el quantum indemnizatorio más que en la delimitación. Es decir, los factores a que se hacen referencia tienen un enfoque prospectivo más retrospectivo, en el sentido de determinar una indemnización que sirva para compensar todas las consecuencias dañosas (morales) que se derivan y derivarán a partir del evento dañoso. Por ejemplo, una sentencia de la Ilustrísima Corte de Apelaciones de Santiago, de fecha 9 de diciembre de 2016, señala que: "SEXTO: Para determinar el quantum del daño extrapatrimonial se debe considerar entre otros aspectos: $1^{\circ}$ la entidad naturaleza y gravedad del suceso o acto que constituye la causa del daño; $2^{\circ}$ la clase de derecho o interés extrapatrimonial agredido; $3^{\circ}$ las consecuencias físicas, psíquicas, sociales o morales que se derivan del daño causado; $4^{\circ}$ su duración y persistencia que impliquen convertirlo en un perjuicio moral futuro; $5^{\circ}$ la culpabilidad empleada por la víctima y, $6^{\circ}$ las condiciones personales de la víctima, entre otros" (énfasis añadido). Corte de Apelaciones de Santiago, 9 de diciembre de 2016, Identificador Thomson Reuters CL/JUR/9046/2016. En el mismo sentido, Corte de Apelaciones de Antofagasta, 27 de octubre de 2008, especialmente considerando $6^{\circ}$. Identificador Thomson Reuters Cl/JUR/3905/2008.

${ }^{45}$ Linacero de la Fuente, cit. (n. 24), p. 1577.
} 
Sin embargo, el argumento aquí nuevamente apunta a un aspecto público y de justicia distributiva. Porque para que el juez sea un "buen juez" debe recurrir a las condiciones sociales imperantes en un lugar y tiempo dados. Esto a su vez implica preguntarse sobre ¿qué es lo que la sociedad considera normalmente tolerable como "molestia" sin derecho a reclamo y aquello que no lo es? Para responder esta pregunta se debe producir una reflexión judicial que considere lo que socialmente constituye un atentado grave a los intereses de la persona, es decir una reflexión de carácter distributivo, porque involucra al colectivo; al grupo social organizado, por cuyo intermedio podrá obtener la información necesaria para determinar lo que es actualmente (tiempo y lugar) una lesión grave y por lo tanto indemnizable, y este razonamiento es de justicia distributiva.

En síntesis, si el juez obra como un "buen juez", con ayuda o no de la tipificación de intereses, es posible obtener información relevante que le permita valorar (ahora sí) en el litigio privado, qué es aquello que constituye un daño moral jurídicamente resarcible y excluir, por consiguiente, daños que son de cargo exclusivo de quien los sufre.

\section{LA DISTRIBUCIÓN DE DERECHOS E INTERESES POR EL DERECHO DE DAÑOS}

\section{Precisiones necesarias}

Hasta hace unas líneas el trabajo se ha centrado en la delimitación del daño moral. Ahora considero relevante señalar dos breves ideas. La primera se refiere a la exclusión de aquellos "daños" que realmente no constituyen un daño moral resarcible. La segunda a señalar los derechos e intereses básicos de la persona que, en determinadas circunstancias, daría pie para su resarcimiento en caso de lesión.

Sobre el primer punto cabe señalar que, de acuerdo al anterior desarrollo de este artículo, no cabe sino concluir que ciertos términos ocupados por la jurisprudencia, principalmente los que se refieren a "molestia" sin más, pueden prestarse para una utilización excesivamente discrecional de la institución del daño extrapatrimonial, no aportando una real conceptuación técnica de cara a una futura delimitación.

Dicho de otra manera, si el concepto de daño moral imperante en la jurisprudencia nacional (y desde luego en el derecho comparado) se refiere al dolor, pesar o molestia, que apunta a la espiritualidad y, en algún sentido, a la psiquis de la persona afectada, el verdadero problema está entonces en la conceptuación de daño extrapatrimonial como pretium doloris sin ajustar sus contornos. Claro está que, si el bien afectado es directamente el cuerpo o 
derechos de la personalidad (en estricto rigor), la subjetividad tiende a menguar frente a la casi evidente vulneración de la persona. Por esa razón, fundar el daño moral simplemente en un pretium doloris es un alto riesgo de subjetividad que puede tender al abuso del derecho de la víctima si no se toman las debidas precauciones. ${ }^{46}$ Siendo ello así, los efectos distorsivos del concepto de daño moral como una subjetividad de la víctima resultan ser perniciosos, e impiden delimitar claramente sus contornos, simplemente porque lo subjetivo es difícilmente comparable objetivamente, mucho menos posible el ser estandarizado.

Por consiguiente, se excluirá la idea de concebir al daño moral únicamente como molestia sin mayor fundamentación, para que, más allá de discutir el dolor, se discutan las vulneraciones de derechos o intereses jurídicamente resarcibles. ${ }^{47}$ Esta idea consiste en abandonar el paradigma de concebir al daño moral únicamente como una institución esencialmente subjetiva, para hablar principalmente de derechos e intereses que sean social y jurídicamente reconocidos como objeto de protección.

Respecto de la segunda cuestión. Es decir, de la distribución de los derechos e intereses que deberán ser tenidos como base para la reparación a favor de los miembros de la sociedad que sufren un daño, considero que -igual que lo razonado más arriba- el derecho debe identificar correctamente aquellos intereses y/o bienes jurídicos que estén dentro de una categoría como resarcible.

Para ello se requiere, en primer lugar, recalcar que a los miembros de la sociedad le son asignados, en una instancia previa y pública, ciertos deberes y derechos primarios. Estos son los que, a raíz de una inspiración rawlsiana, ${ }^{48}$ Papayannis denomina como derechos y deberes de indemnidad. ${ }^{49}$ Es decir, el deber de no dañar y el derecho a no ser dañado en determinadas circunstancias (de manera dolosa, culposa o a través de conductas riesgosas).

\footnotetext{
${ }^{46}$ En este sentido, Barrientos Zamorano, cit. (n. 12), p. 93. El autor da cuenta de la constante crítica hacia la conceptuación de daño moral como pretium doloris. Desde luego supone una versión del daño extrapatrimonial que supere el aspecto meramente subjetivo y se centre en la vulneración de derechos más que en el dolor de la víctima. Así, afirma que: "Por ello, como hemos apuntado más arriba, hoy se prefiere discutir sobre el carácter patrimonial o no patrimonial del derecho lesionado o también llamado extrapatrimonial". En el mismo sentido BrebBiA, Roberto, El daño moral, Orbir, Rosario, 1967, p. 67.

${ }^{47}$ Esta idea se refiere a que quizá la lógica del daño moral pase del pretium doloris a la lógica de derechos e intereses, que el dolor (que bien puede existir) no sea la única razón por la que se otorgue una indemnización, que haya a lo menos mayor argumentación judicial.

${ }^{48}$ Rawls, John, Teoría de la Justicia (Trad. María Dolores González), Fondo de Cultura Económica, México D.F., 1995.

${ }^{49}$ Papayannis, cit. (n. 1), pp. 318 y ss.
} 
Luego, en cuanto al contenido normativo del deber y, particularmente del derecho a no ser dañado, dependerá fundamentalmente de los límites de la libertad de acción del posible agente dañador y de la seguridad de las posibles víctimas que cada sociedad determine como relevante a través de consideraciones distributivas, como lo serían los derechos básicos y fundamentales consagrados en la Constitución Política de la República: el derecho a la vida, la integridad física y psíquica, la honra y el honor, la libertad y la propiedad por nombrar algunos.

Seguidamente, identificar si en todos los casos de vulneración de algunos de los derechos fundamentales de las personas constituyen inmediatamente un daño moral resarcible es algo que debe ser resuelto en concreto por el juez, pues la estructura básica de los derechos y deberes, sumados a las circunstancias sobre las cuales se desarrolla el daño, permitirán al tribunal determinar correctamente la infracción del deber de no dañar y el derecho que le compete a la víctima como fundamento de su reclamación.

En concreto, nuevamente se requerirá la actuación de lo que he denominado como "buen juez", es decir, aquel que está al tanto de los valores sociales que sirven para establecer qué es indemnizable moralmente.

Por ejemplo, no será lo mismo entablar una reclamación por ser llamado homosexual en una sociedad fuertemente liberal en lo social y familiar, comparada a una en donde ser homosexual puede ser socialmente un deshonor o descrédito grave, como lo es en sociedades más conservadoras. En este sentido, de manera inicial, el juez tiene antecedentes objetivos que le permiten discernir e interpretar razonablemente qué es aquello que cuenta como un cierto tipo de daño moral. El juez de la sociedad liberal tenderá a ser más reacio a la reparación, en cambio, en el segundo caso, quizá haya una argumentación mucho más elaborada en términos de fundamentar una sentencia condenatoria.

Razonar entonces de esta forma, implica estructurar los derechos y deberes de los miembros de la sociedad en un sentido colectivo y público, y tal proceder no puede ser sino de justicia distributiva.

\section{El litigio. Justicia distributiva y correctiva}

Sobre la aplicación de las consideraciones distributivas que puedan estar involucradas en la reparación del daño moral, es necesario complementarlas con criterios de justicia correctiva.

Ya se sabe que la justicia distributiva y la justicia correctiva son dos modos de comprender las interacciones sociales, la primera se refiere a un aspecto 
público y de relación proporcional entre los miembros de una comunidad, ${ }^{50}$ y la segunda a la relación directa entre las partes, una suerte de mecanismo privado de interacción que rige los tratos voluntarios e involuntarios. ${ }^{51}$ Ambas tienen la pretensión de preservar la igualdad de los agentes que interactúan, en la justicia distributiva de naturaleza proporcional, en la correctiva, aritmética.

Sobre el punto que nos convoca, y dada la conceptuación que he recogido sobre, particularmente, el derecho de daños como una combinación de ambos criterios de justicia, considero relevante referirme finalmente a aquellos dos aspectos, de manera resumida, con miras a concluir este trabajo.

Así, si para distribuir derechos e intereses válidos, en tanto son considerados a lo menos como fundamento para una futura reclamación que pretenda el resarcimiento de un daño, el razonamiento debe pasar por la primera instancia, es decir, pública y distributiva. Esto quiere decir que el deber de no dañar y el derecho a no ser dañado constituyen la primera premisa distributiva de los intereses de las partes. Dicha premisa permite reflexionar, ya más en concreto, sobre los límites de la libertad de acción frente a la seguridad de cada agente, respectivamente.

No obstante lo anterior, cuando el daño se produce y si nada ha hecho la víctima para reclamar de aquella situación, entonces no hay nada que resolver. Por más que los derechos y deberes estén distributivamente asignados a cada agente, y el derecho en concreto de la víctima se vea leve o severamente perjudicado, nada hay que adjudicar si no ha hecho uso del aparato estatal. Por consiguiente, se requiere de un ejercicio adicional que lleve a las partes a ser confrontadas entre sí, de una manera directa y relacional, en donde el demandante esté unido normativamente con el demandado. ${ }^{52}$ Desde luego, se requiere de la aplicación de la justicia correctiva. Es aquí en donde el juez, confrontada que sean las partes, debe adjudicar ya no el deber, sino la responsabilidad del agente dañador y determinar el derecho afectado de la víctima, cumplidas las condiciones requeridas por el ordenamiento jurídico determinado.

\footnotetext{
${ }^{50}$ Aristóteles, Ética a Nicómaco (Trad. Salvador Rus Rufino y Joaquín E. Meabe), Tecnos, Madrid, 2011, 1131 a.

${ }^{51}$ Aristóteles, cit. (n. 50), 1131b y $1131 \mathrm{a}$.

${ }^{52}$ WeINRIB, La idea ... cit. (n. 7), p. 96 . El autor señala lo siguiente sobre la justicia correctiva, en cuanto permite comprender la interacción entre los agentes: "Presentar la justicia correctiva como igualdad cuantitativa refleja el rasgo fundamental del derecho privado: un demandante concreto demanda a un demandado concreto. La ganancia y pérdida injustas no son cambios mutuamente independientes en las posesiones de las partes; si lo fueran, la pérdida y la ganancia podrían ser remediadas mediante dos operaciones independientes. Pero puesto que el demandante ha perdido lo que el demandado ha ganado, una única responsabilidad vincula a la persona concreta que ha ganado con la persona concreta que ha perdido".
} 
Una pregunta recurrente, sobre el proceso de adjudicación que tiene lugar mediante la aplicación de la justicia correctiva, es si este principio de justicia es autónomo o, por el contrario, contribuye a definir los derechos y deberes de las partes, es decir si contribuye a definir los derechos y deberes que son asignados en la etapa distributiva. La verdad es que esta pregunta suele ser excesiva para el tenor de estas breves líneas, por lo que sólo se finalizará con señalar que es el juez, ya ahora en el litigio privado, el llamado a adjudicar los derechos de las partes, delimitando sus contornos a través de consideraciones distributivas y luego reducidas ellas al ámbito eminentemente privado, demandante-demandado.

De hacer aquella reflexión podrá actuar como un "buen juez", que le permita comprender de mejor forma la interacción completa de las partes. De justicia distributiva, preservando la igualdad proporcional, en el ámbito colectivo y público. Y de justicia correctiva, preservando la igualdad aritmética, en la adjudicación concreta en el litigio de las partes, es decir en la relación directa entre demandante y demandado.

\section{CONCLUSIONES}

1. Este trabajo ha tenido por objetivo presentar algunas consideraciones distributivas en el resarcimiento del daño moral, por responsabilidad contractual y extracontractual, dando primacía a este segundo ámbito de aplicación.

2. Del análisis puede concluirse que la dogmática tradicional y la jurisprudencia de la segunda mitad del siglo XX y comienzos del presente, sostienen aún una visión eminentemente subjetiva del daño extrapatrimonial, principalmente como pretium doloris.

3. La conceptuación excesivamente subjetivista ha llevado a determinar que, prácticamente, toda molestia puede ser constitutiva de daño moral, lo cual se ve reflejado en la responsabilidad extracontractual, pero con mayor fuerza en la responsabilidad por incumplimiento de contrato.

4. Para resolver no la conceptuación, pero sí la delimitación del daño moral en el derecho de contratos, es necesario referirse a la previsibilidad tanto como límite de la indemnización y también como un mecanismo que sirve para identificar los riesgos asumidos por el deudor. Dichos factores junto a una interpretación armónica del artículo 1546 del Código Civil, y las circunstancias que rodean la celebración de la convención, permitirán identificar los intereses resguardados por la regla contractual.

5. En el ámbito extracontractual, partiendo de un análisis crítico de la conceptuación y delimitación del daño moral, es necesario que el juez comprenda la interacción completa de los agentes. Esto significa que debe 
tener presente las consideraciones de justicia distributiva en la interacción, para luego referirse a las de justicia correctiva.

6. Respecto de la justicia distributiva, debe identificar cuáles son los valores e intereses sociales que puedan ser aceptados como base para una legítima reclamación. Aquello dependerá de lo que la sociedad estime como relevante en un momento y lugar determinados.

7. Verificada en la etapa distributiva los derechos, deberes e intereses de las partes, se requiere la adjudicación judicial de la libertad de acción y la seguridad, esto es, determinar si se ha infringido el deber de no dañar y el derecho a no ser dañado. Luego, establecido que sea el derecho o interés específico que se ha vulnerado, se puede rectificar la interacción injusta, compensado a la víctima y preservando -entonces- la igualdad de los agentes.

\section{BIBLIOGRAFÍA CITADA}

Alessandri Rodríguez, Arturo, De la responsabilidad extracontractual en el Derecho Civil Chileno, Imprenta Universitaria, Santiago, 1943.

ARistóteles, Ética a Nicómaco (Trad. Salvador Rus Rufino y Joaquín E. Meabe), Tecnos, Madrid, 2011.

BARRIENTOSZAMORANo, Marcelo, "Del daño moral al daño extrapatrimonial: la superación del pretium doloris", Revista Chilena de Derecho, 2008, Vol. 35 $\mathrm{N}^{\mathrm{o}}$ 1, pp. 85-106.

Barros Bourie, Enrique, Tratado de Responsabilidad Extracontractual, Editorial Jurídica de Chile, Santiago, 2006.

Barros Errázuriz, Alfredo, Curso de Derecho Civil. Segundo Año, Editorial Nascimiento, Santiago, 1932.

BReBBia, Roberto, El daño moral, Orbir, Rosario, 1967.

Butrón FIRPO, Roberto, "La indemnización del daño moral en nuestra legislación" en Tavolari, R. (Director) Doctrinas Esenciales Derecho Civil. Responsabilidad Extracontractual, Editorial Puntolex, Santiago, 2009.

CÁrdenas Villarreal, Hugo, "Sobre la extensión de la reparación del daño moral derivado de contrato", Revista Chilena de Derecho, 2004, vol. 31 No 2, pp. 379-387;

Cárdenas Villarreal, Hugo, "Daño moral por incumplimiento de contrato", Revista Chilena de Derecho, 2006, Vol. 33, № 3, pp. 585-593.

CoAse, Ronald, "The Problem of Social Cost". The Journal of Law and Economics, 1960, № 3, pp. 1-44.

Corral Talciani, Hernán, Contratos y daños por incumplimiento, Abeledo Perrot, Santiago, 2011. 
Corral Talciani, Hernán, Lecciones de responsabilidad civil extracontractual, LegalPublishing, Santiago, 2013.

De la Maza Gazmuri, Iñigo, "Las cuentas corrientes y el dolor" en Mercurio Legal (7 de septiembre de 2016) Disponible en línea: www.elmercurio. com/Legal/Noticias/Analisis-Juridico/2016/09/07/Las-cuentas-corrientes-y-eldolor.aspx

Diez-Picazo, Luis, Derecho de Daños, Civitas, Madrid, 1999.

Diez-Picazo, Luis, El escándalo del daño moral, Civitas, Madrid, 2008.

Diez Schwerter, José Luis, El daño extracontractual, Editorial Jurídica de Chile, Santiago, 2012.

Domínguez Hidalgo, Carmen, El daño moral, Editorial Jurídica de Chile, Santiago, 2000.

Domínguez Hidalgo, Carmen "La reparación del daño moral derivado del contrato en el derecho civil chileno: realidad y límites", en De la Maza G., I. (Director), Cuaderno de Análisis Jurídico III. Temas de Contratos, Santiago, Fundación Fernando Fueyo, 2006, pp. 227-244.

Domínguez Hidalgo, Carmen, "El daño moral en Chile: Contornos y problemas", Revista Anales Derecho UC, número 1, Editorial Legis, Santiago, 2006, pp. 307-328.

Domínguez Águila, Ramón; Domínguez Benavente, Ramón, "Daño moral en la responsabilidad contractual. Ausencia de una norma excluyente de reparación”, Revista de Derecho Universidad de Concepción, 1994, N 196, pp. 155-160.

Fueyo LANeri, Fernando, "Sobre el daño extrapatrimonial en el incumplimiento de contrato", Revista Jurídica de Buenos Aires, 1965, pp. 67110.

Fueyo LANERI, Fernando, "De nuevo sobre el daño extrapatrimonial en el cumplimiento de contrato", Colección Justitia et Jus, Sección de Investigaciones, $1972, \mathrm{~N}^{\circ} 8$.

Gatica Pacheco, Sergio, Aspectos de la indemnización de perjuicios por incumplimiento de contrato, Editorial Jurídica de Chile, Santiago, 1959.

GonzÁlEz CAZorla, Fabián, "Ilicitud y justificación: algunas notas sobre la antijuridicidad en el derecho de daños chileno", Revista de Derecho Civil, 2016, Vol. III No 2, pp. 147-169.

Guzmán Brito, Alejandro, Derecho Privado Romano, Editorial Jurídica de Chile, Santiago, 2012.

LinaCero de la Fuente, María, "Concepto y límites del daño moral: el retorno al pretium doloris". Revista Crítica de Derecho Inmobiliario, 2010, N ${ }^{\circ}$ 720, pp. 1559-1594.

López Santa María, Jorge, Los Contratos. Parte General, LegalPublishing, 
Santiago, 2010, $5^{\text {a }}$ edición.

Martin-Casals, Miquel; Ribot, Jordi; Solé, Joseph, "El daño moral”, en Cámara, Sergio (coord.), Derecho Privado Europeo, Colex, Madrid, 2003, p. 857-881.

PaPAYANNIS, Diego M., Comprensión y justificación de la responsabilidad extracontractual, Marcial Pons, Madrid, 2014.

Papayannis, Diego, Derecho de daños, principios morales y justicia social, Marcial Pons, Madrid, 2014.

PAPAYANNIS, Diego, El derecho privado como cuestión pública, Ediciones Universidad Externado de Colombia, Bogotá, 2016.

Pino EMHART, Alberto, "Entre la reparación y la distribución: La responsabilidad civil extracontractual como mecanismo de distribución de infortunios", Revista Chilena de Derecho Privado, 2013, No 21, pp. 89-135.

Posner, Richard, "The concept of Corrective Justice in Recent Theories of Tort Law", The Journal of Legal Studies, 1981, № 10, pp. 187-206.

Rawls, John, Teoría de la Justicia (Trad. María Dolores González), Fondo de Cultura Económica, México D.F., 1995.

RodRíGuEz GuITIÁN, Alma, "La reparación del daño moral en la contratación inmobiliaria", Revista de Derecho Universidad del Norte, 2008, № 30, pp. 141163.

Tomasello Hart, Leslie, El daño moral en la responsabilidad contractual, Editorial Jurídica de Chile, Santiago, 1969.

WeInRIB, Ernest, Corrective Justice, Oxford University Press, Oxford, 2012.

Weinrib, Ernest, La idea de Derecho Privado (Trad. Eze Páez), Marcial Pons, Madrid, 2017. 